\title{
Implementation of the task "Optimization of the use of blood components and blood products" as part of the health policy program "Ensuring the self-sufficiency of the Republic of Poland in blood and blood components for the years 2015-2020"
}

\author{
Activities of the Institute of Hematology and Transfusion Medicine \\ in the period 2019-2020
}

\author{
Jolanta Antoniewicz-Papis®, Agata Mikołowska®, Krzysztof Sutkowski, \\ Paweł Kłobukowski, Krystyna Dudziak, Magdalena Łętowska๑
}

Department of Transfusion Medicine, Institute of Hematology and Transfusion Medicine, Warsaw

\section{Introduction}

In reference to the materials published in Journal of Transfusion Medicine [1,2] regarding implementation of the health policy program "Ensuring the self-sufficiency of the Republic of Poland in blood and blood components for 2015-2020" with regard to the task "Optimization of the use of blood components and blood products" the Department of Transfusion Medicine of the Institute of Hematology and Transfusion Medicine (Institute) presents a report on the realization of this program in the 2019-2020 period.

As mentioned in the previous publications $[1,2]$, the main aim of this health-policy program financed by the Minister of Health is to ensure self-sufficiency of the Republic of Poland in blood and blood components as well as to strengthen the safety of blood and blood components.

Pursuant to the Agreement of August 18th 2017 between the Institute of Hematology and Transfusion Medicine and the Minister of Health (Agreement No. NCK-F/UM/PPZ/69/2017) in the year 2019 the Institute was obliged to fulfill the following specific objectives:
- perform on-site training dedicated to professionals involved in the supervision over blood transfusion in hospitals and to members of transfusion committees;

- update the publication "Standard for Activity of the Transfusion Committee";

- run the e-learning platform.

In the year 2020, the specific objectives to be fulfilled by the Institute following the provisions of this Agreement were to:

- perform on-site training dedicated to the personnel involved in the supervision of blood transfusion in hospitals and to members of transfusion committees;

- update and run the e-learning platform;

- publish the "Standard for Activity of the Transfusion Committee" in electronic form.

Implementation of Agreement provisions for 2019

According to schedule provided by the Agreement, in the period January $1^{\text {st }}$ - December $31^{\text {st }}$ 2019, the employees of the Department of Transfusion Medicine of the Institute were engaged in parallel performance of the following activities:

Adres do korespondencji: dr hab. n. o zdr. Jolanta Antoniewicz-Papis, Department of Transfusion Medicine, Institute of Hematology and Transfusion Medicine in Warsaw, Indiry Gandhi Street 14, 02-776 Warsaw, phone: (22) 349 63 91, e-mail: jpapis@ihit.waw.pl Translation: mgr Krystyna Dudziak

This article is available in open access under Creative Common Attribution-Non-Commercial-No Derivatives 4.0 International (CC BY-NC-ND 4.0) license, allowing to download articles and share them with others as long as they credit the authors and the publisher, but without permission to change them in any way or use them commercially. 
- organization and realization of training courses for professional groups - members of transfusion committees: doctors, nurses/midwives, laboratory diagnosticians, doctors responsible for blood management and other personnel directly involved in activities related to transfusion and supervision over transfusion of blood and blood components;

- running the e-learning platform dedicated to employees of hospitals - members of the transfusion committees, staff involved in activities related to transfusion medicine and supervision in hospitals.

- organization of expert-meetings, development of supplementary educational material and ultimately - preparation of a new (up-dated) version of the "Standard for Activity of the Transfusion Committee".

\section{Training courses}

\section{Preparatory actions}

As mentioned in the previous publication, on June $11^{\text {th }} 2018$, as result of the public procurement procedure, the Institute signed a three-year contract with Global Congress Sp. $z$ o. o. for organization of 18 (two-day) training courses. The three-year period gave space for better planning of exact dates of individual courses. Annually however, the Agreement had to be annexed to guarantee the transfer of public funds for the current year. Two-day training courses were planned for each of the professional groups involved in the activity of transfusion committees, i.e.: doctors, nurses/midwives, laboratory diagnosticians, doctors responsible for blood management and other personnel directly involved in activities related to blood transfusion and supervision of blood transfusion therapy. The recruitment of participants for training courses was performed by the contracted company based on the information and contact-data provided by the Institute.

Following the analysis of post-training opinions and comments referring to 2017-2018 lectures, the authors verified their presentations and in 2019 the trainees were offered:

- educational material - compact version of lectures presented and discussed during the on-site training course (presentation of selected slides);

- supplementary training materials;

- certificates for participants who completed the training course (certificate-template provided by the Institute);

- anonymous assessment-questionnaires for participants, prepared by the Institute in cooperation with the Contractor.
Pursuant to the Agreement, training courses were to be conducted only by lecturers approved by the Institute to ensure an appropriate, high-quality standard of knowledge. In 2019 the lecturing-team consisted of 6 lecturers from the Institute and 3 persons from other medical centers (9 lecturers in all). The overall content of the training courses covered the same issues as in the previous years and was adapted to the needs of individual professional groups: doctors, nurses, laboratory diagnosticians. The issues were as follows:

- blood transfusion service in Poland, with particular emphasis on legal acts, organization of blood transfusion therapy in hospitals;

- blood components, blood products, safety;

— indications for use of blood components, blood products; principles of patient blood management (PBM); autotransfusion;

- the role of nurse in the process of transfusion;

- tasks of the laboratory of immunohematology and the blood bank;

- therapeutic procedures;

- aspects of safe transfusion;

- adverse events and reactions; clinical cases;

- immunohematology; significance for safe transfusion of blood components;

- cooperation of the hospital ward with laboratory for immunohematology and the blood bank;

- elements of risk management, hemovigilance;

- appropriate provision of blood components;

- importance of computerization/IT in transfusion medicine;

- tasks of transfusion committee, doctor responsible for blood management, nurse/midwife and laboratory diagnostician in the transfusion process.

\section{Realization of training}

All training courses were conducted in Warsaw, at the Best Western Hotel FELIX situated at Omulewska St. 24. The schedule was as follows:

\section{Course I:}

- 16-17 May 2019 - training course for diagnosticians;

- 30-31 May 2019 - training course for nurses/ /midwives;

- 11-12 June 2019 - training course for doctors; Course II:

- 26-27 September 2019 - training course for diagnosticians;

- 10-11October 2019 - training coursefornurses/ /midwives;

- 17-18 October 2019 - training course for doctors. 
As in the previous years, classes for each professional group were conducted on two consecutive days. On the first day the trainees attended 8 hours of lectures and on the second one they had 7 hours of lectures, and additionally an anonymous assessment-questionnaire to complete, a final test to take and "The Strange Case of Penny Allison" movie to watch ${ }^{1}$. Each lecturer contributed with his own questions and answers to the final test and answer-key. Representatives of the Institute were present on-site during each training course for the purpose of observation and support.

In 2019, a total of $\mathbf{2 5 2}$ persons from all regions of Poland participated in both cycles of stationary courses; $\mathbf{8 4}$ doctors, $\mathbf{8 4}$ nurses/midwives and $\mathbf{8 4}$ laboratory diagnosticians. All trainees succeeded in completing the course and were granted Certificates and Educational Points for participating in the training.

As in previous years, the outcome of anonymous assessment-questionnaire revealed that both the subjects of lectures as well as the organization of training were rated very high. On a 5-point scale, the average value for lecture-content was $\mathbf{4 . 8 0}$ points and for organization of training $-\mathbf{4 . 6 5}$ points.

Analysis of test results, anonymous assessment - questionnaires and collective summary of these questionnaires were helpful for verification of the educational material for future training courses and for update of the educational material to be uploaded on the e-learning platform.

\section{Running the e-learning platform}

Pursuant to the provisions of Annex No. 2 of March $5^{\text {th }} 2019$ to the Agreement No. NCK F/ /UM/PPZ/69/2017 of August 18 ${ }^{\text {th }}, 2017$, one of the obligations of the Institute for the year 2019 was to run a public e-learning platform dedicated to hospital employees, members of transfusion committees, persons supervising transfusion therapy and involved in activities related to transfusion medicine in hospitals and laboratories. The aim was to provide professionals with the opportunity of distance learning in the field of transfusion medicine. The issues presented on the platform were prepared in 2018 and they were compatible with the issues presented during on-site training.

\section{Realization of the task}

As part of this task, the Institute monitored the functioning of the e-learning platform which be-

\footnotetext{
${ }^{1}$ In 2017, the Institute was granted permission to use of the English film "The Strange Case of Penny Allison" for training purposes.
}

came accessible as of November $30^{\text {th }} 2018$ at www. krwiolecznictwo-szkolenia.edu.pl. The content of the platform was dedicated to employees of hospitals, members of transfusion committees, persons involved in supervision of transfusion therapy and all participants in transfusion medicine procedures in hospitals and immunohematology laboratories. The aim was to provide distance learning in transfusion medicine through:

- uninterrupted running and administration of the platform:

- monitoring platform-performance;

- provision of technical support for platform users;

- creation and management of accounts and authorization of platform users;

- cooperation with the Contractor;

- providing answers to questions addressed to experts (lecturers);

- promotion of the platform among hospital staff and medical personnel;

- promotion of the platform on the Facebook social network site.

Activities related to 2019 update of the "Standard for Activity of the Transfusion Committee"

As mentioned in the previous publication [1], the "Standard for Activity of the Transfusion Committee" was published in 2017, as result of cooperation between experts from the Institute and specialists from other medical centers. In 2019, a new up-dated version of the "Standard for Activity of the Transfusion Committee" was developed on the basis of opinions and comments about the 2017 version, protocols on the activity of transfusion committees and blood establishment inspections as well as the current state of knowledge. For this purpose:

- uniform templates were prepared for analysis of 2018 protocols from blood establishment inspections performed as part of supervision over blood transfusion service as well as of reports on the activity of transfusion committees;

- tools were prepared for analysis of the content of these templates, supplemented by the persons responsible for the analysis;

- a comprehensive analysis of the protocols was performed;

- the content of the 2017 chapters was expanded and/or updated;

- new chapters were added;

- a new version of the entire document was developed. 
During the up-date process, the authors referred to the latest publications related to transfusion medicine as well as to new or updated legal acts. Among others, they drew upon the content of 5 most recent items of professional literature published in English that were purchased with the aim of supporting the program.

All changes to the text of the "Standard for Activity of the Transfusion Committee" were listed down and a new graphic design was proposed (Fig. 1).

\section{Implementation of Agreement provisions for 2020}

\section{Training courses}

As in the previous years, plans were made to conduct on-site/classroom training for hospital employees, members of transfusion committees, persons supervising transfusion therapy and involved in activities related to transfusion medicine in hospitals and immunohematology laboratories. Pursuant to the Contract of 2018, two cycles (spring and autumn) of stationary training courses were planned (6 in all). The first two-day training course took place on February $27^{\text {th }} / 28^{\text {th }} 2020$ and was dedicated to laboratory diagnosticians. A total of 37 persons participated in this course which had comparable rating to the previous courses: $\mathbf{4 . 8 9}$ points for the lecture content and $\mathbf{4 . 6 7}$ points for organization (5-point scale).

Then came the outbreak of SARS-CoV-2 pandemic which dramatically changed the sequence of events. The dates of the consecutive training sessions had to be adjusted to the dynamically changing epidemiological situation and finally stationary training had to be postponed until autumn 2020. In view of the anticipated lockdown also in autumn and restrictions with regard to assemblies (training included) a decision was made to change the formula of training from on-site to on-line. Pursuant to this decision, the Institute employees involved in the project started searching for solutions that would allow to conduct training in a form as close to stationary training as possible. Several meetings were held with the Contractor of 2018 to discuss the details for switching to the on-line formula. In July 2020, the Contractor confirmed the willingness, ability and potential to conduct on-line training. In September 2020 however, he withdrew the readiness to fulfill the assignment and the Contract was terminated.

In consequence, the Institute project team took advantage of the knowledge gained from investigation in on-line trainings and prepared

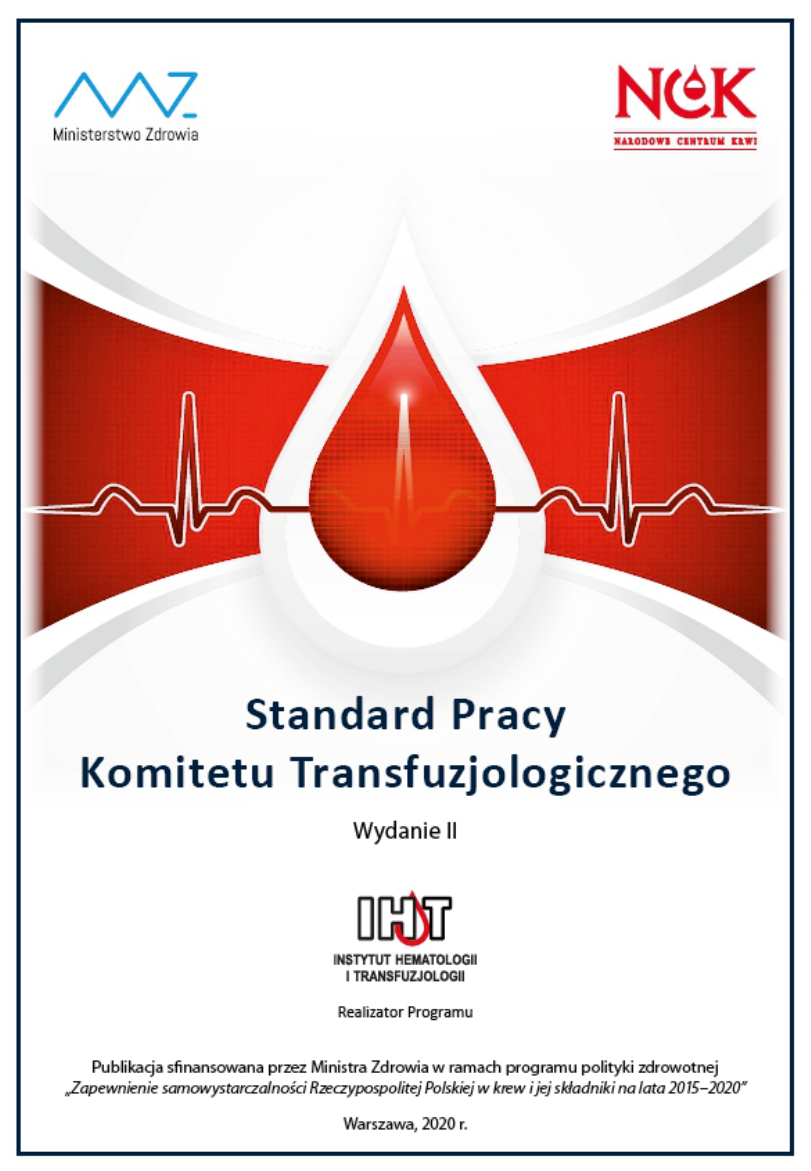

Figure 1. Cover of the "Standard for Activity of the Transfusion Committee" - electronic publication

requests for proposal addressed to 4 companies, two of which responded. The most favorable pricing was offered by Workin company which was ultimately selected. All these moves were made under time pressure and threat to realization of the project as brought about by the SARS-CoV-2 pandemic.

In the new circumstances the tasks of the Institute included:

- countrywide notification of chairmen of transfusion committees, doctors responsible for blood management, heads of laboratories for immunohematology and chief nurses about the shift to on-line training formula;

- preliminary registration of participants; verification of no previous participation in the training courses (under the provisions of the Agreement, the same person could participate only once);

- putting together the educational material (from all lecturers);

- preparing concise supplementary training materials ready for sending to registered trainees; 
- mailing of educational materials and certificates to registered trainees.

The tasks of the Contractor included among others:

- development of an IT platform for conducting 5 two-day distance learning courses in the form of videoconferences;

- providing premises for delivering lectures and related activities in the sanitary regime imposed by the pandemic;

- provision of computer hardware and software indispensable for effective and trouble-free on-line training;

- performing all indispensable activities related to handling of lecturers and trainees (moderation and technical assistance), including:

- monitoring of performance for security of participants and their personal data;

- protection of the platform and educational content against unauthorized access;

- support in registration of trainees and lecturers on the platform;

- recording of the training course;

- providing the Institute team with support as well as with information relevant to realization of the task and the obligation to settle the transaction, in particular:

- preparation of a daily educational documentary and supervision over proper document keeping;

- preparation of name-lists confirming participation in each training course;

- technical elaboration of a personalized final test; support to the lecturer during the test and the discussion;

- technical elaboration of anonymous trainingassessment survey for all trainees and preparation of a collective summary of the outcome.

All the training courses were conducted online via the Clickmeeting platform on the premises of the Workin company. The conditions ensured good quality of lecture presentation and continuous technical support for both trainees and lecturers. The Institute employees could participate in the classes on line as observers offering support whenever required.

The training courses were held on the following dates:

- 29-30 October 2020 - training for doctors;

- 2-3 November 2020 - training for nurses;

- 9-10 November 2020 — training for diagnosticians;

- 12-13 November 2020 - training for doctors;

- 30 November-1 December 2020 - training for nurses.
A total of $\mathbf{2 6 0}$ persons participated in the online training. Educational materials and certificates were sent to participants by e-mail.

In 2020, a total of $\mathbf{2 9 7}$ persons from all regions of Poland participated in both on-site and on-line courses, In this number 94 persons participated in the training course for doctors, $\mathbf{9 2}$ in the course for nurses/midwives and $\mathbf{1 1 1}$ in the courses for laboratory diagnosticians.

Participants were offered the opportunity of active participation, just like in stationary training, i.e. transmission of image (video) and sound. Additionally, the lecturers made attempts to activate their audience. Certificates and educational material were sent to all participants. On-line trainings were rated high. On a 5-point scale, the lecture content on average was granted more than $\mathbf{4 . 8 2}$ points and over $\mathbf{4 . 7 8}$ points were given for organization.

\section{Updating and running the e-learning platform in 2020}

With regard to the content update the following tasks were planned:

- review and verification of all materials already available on the e-learning platform;

- preparation of new materials in the form of films and presentations, among others based on the opinions and comments from on- site training courses;

- authorization of new materials by individual lecturers following editorial changes;

- technical elaboration of the new materials;

- consultations between lecturers and the Contractor regarding the changes that were introduced;

- acceptance of the final version of the new materials before recording;

- recording of new lectures;

- recording of modified, updated materials posted on the platform in 2018.

Basically, all the films prepared in 2018 required modification and up-dating with regard either to the current state of knowledge or changes in legal regulations. Moreover, the epidemic enforced changes in the organization of recordings and the method of preparing educational materials.

In addition, the platform features new materials in various formats (ppt, pdf, pps, mp4) and includes extended information on the issues presented in the basic training module as well as other issues related to transfusion medicine. The platform also contains information (link) on the new version of the "Standard for Activity of the Transfusion Committee". 
Publication of the electronic version of the "Standard for Activity of the Transfusion Committee"

The "Standard for Activity of the Transfusion Committee" developed in 2019, was prepared for publication in electronic version. The final graphic design of the whole publication as well as the cover design had to be approved by the National Blood Center (NCK) under the provisions of the Agreement.

In order to obtain the highest possible quality of the electronic publication, a decision was made to outsource the task to a professional company. Ultimately the document was published in three formats (pdf, epub, mobi) on the Institute website and the e-learning platform.

Summary of four-year activity of the Department of Transfusion Medicine with regard to implementation of the task "Optimization of the use of blood components and blood products" as part of the health policy program entitled "Ensuring the self-sufficiency of the Republic of Poland in blood and blood components for 2015-2020"

Since the Agreement No. NCK-F/UM/PPZ/ $/ 69 / 2017$ was signed on August $18^{\text {th }} 2017$, the employees of the Department of Transfusion Medicine have performed the following activities related to the implementation of the project:

1. During both stationary (on-site) and on-line training a total of 21 courses were organized and a total of 919 professionals from all regions of Poland completed training:

- 7 courses for doctors (290 persons);

- 7 courses for nurses / midwives (307 persons);

- 7 courses for diagnosticians (322 persons trained);

Certificates of completion of the training course were granted to all participants.

2. Two editions of the "Standard for Activity of the Transfusion Committee" were developed (in 2017 and an up-date in 2020) and published in three formats (pdf, epub and mobi) in 2017 and 2020.

3. Launching of a public e-learning platform dedicated to members of transfusion committees: doctors, nurses/midwives, laboratory diagnosticians, doctors responsible for blood management and other personnel directly involved in activities related to transfusion and supervision over transfusion of blood and blood components. By the end of 2020, there were 4,439 user-accounts registered on the platform, 4,103 of which were confirmed, and $\mathbf{1 , 8 1 7}$ people were issued certificates confirming the completion of the training course.

The opinions forwarded in assessment-questionnaires as well as comments provided via platform and during direct conversations confirmed positive feedback from participants. They emphasized the high level of educational content and commitment of lecturers as well as efficient organization of both stationary and on-line courses.

One of the most frequently asked questions referred to the possibility of extending access to the platform beyond 2020 as well as using the platform for training that would authorize nurses/ /midwives to transfuse blood and blood components.

Noteworthy is the fact that the most common obstacle to participation in distance learning were technical problems (e.g. unstable internet connection or no access to internet). For this reason, it is advisable that distance training in real time is complementary with e-learning by asynchronous methods (platform www.krwiolecznictwo-szkolenia.edu.pl), where the participant himself decides about the training time and pace. This however leaves no chance for real-time discussions.

The presented project-summary indicates the importance of continuing such training activities for the benefit of transfusion medicine.

\section{References}

1. Antoniewicz-Papis J., Mikołowska A., Łętowska M. Realizacja zadania „Optymalizacja składników krwi i produktów krwiopochodnych" w ramach programu polityki zdrowotnej pn. „Zapewnienie samowystarczalności Rzeczypospolitej Polskiej w krew i jej składniki na lata 2015-2020". Działania Instytutu Hematologii i Transfuzjologii w 2017 roku - informacje pilotażowe”. J Transf Med 2018; 11 (1): 33-37.

2. Antoniewicz-Papis J, Mikołowska A, Sutkowski K, et al. Realizacja zadania „Optymalizacja stosowania składników krwi i produktów krwiopochodnych” w ramach programu polityki zdrowotnej pn. „Zapewnienie samowystarczalności Rzeczypospolitej Polskiej w krew i jej składniki na lata 2015-2020". J Transf Med. 2019; 12(1): 13-34, doi: 10.5603/jtm.2019.0013. 